La revue La revue pour l'histoire du CNRS

POUR L'HISTOIRE DU CNRS

16 | 2007

L'expertise scientifique

Les 100 plus belles découvertes d'Orsay. 1955-2005

Collectif, sous la direction de René Bimbot. Vuibert, 2005

Isabelle Martelly

\title{
CpenEdition
}

Journals

Édition électronique

URL : https://journals.openedition.org/histoire-cnrs/1518

DOI : 10.4000/histoire-cnrs. 1518

ISSN : 1955-2408

Éditeur

CNRS Éditions

Édition imprimée

Date de publication : 3 avril 2007

ISBN : 978-2-271-06453-0

ISSN : $1298-9800$

Référence électronique

Isabelle Martelly, «Les 100 plus belles découvertes d'Orsay. 1955-2005 », La revue pour l'histoire du CNRS [En ligne], 16 | 2007, mis en ligne le 20 mars 2007, consulté le 20 mai 2021. URL : http:// journals.openedition.org/histoire-cnrs/1518; DOI : https://doi.org/10.4000/histoire-cnrs.1518

Ce document a été généré automatiquement le 20 mai 2021

Comité pour l'histoire du CNRS 


\section{Les 100 plus belles découvertes d'Orsay. 1955-2005}

Collectif, sous la direction de René Bimbot. Vuibert, 2005

Isabelle Martelly

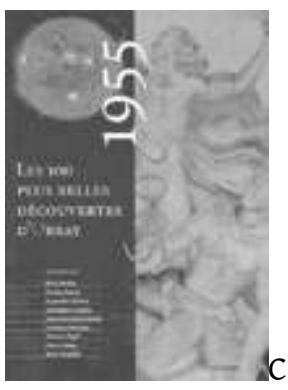

Ce campus de l'université d'Orsay (actuellement université Paris XI) a 50 ans, une jeunesse en comparaison des vénérables universités de France et de Navarre qui peuvent s'enorgueillir de plusieurs siècles d'âge. Pourtant quelle moisson de découvertes et d'idées originales a émergé de ce lieu pendant ces cinquante dernières années!

1 À la fin des années 1950, certains chercheurs avaient délaissé le quartier latin pour tenter l'aventure. Il s'agissait d'investir un lieu neuf où les idées originales pouvaient jaillir, à condition de chausser des bottes pour affronter la boue des chemins entre la gare du Guichet et « la Fac ». Ces pionniers du campus d'Orsay et leurs successeurs ont été productifs à en juger Les 100 plus belles découvertes d'Orsay - 104 en réalité -, qui sont rapportées dans un livre publié sous la responsabilité de René Bimbot, physicien de l'Institut de physique nucléaire de Paris XI.

2 Raconter les " découvertes d'Orsay ", quel peut être l'objectif d'une telle entreprise ? Il s'agit de jeter un regard rétrospectif sur la validité et la pertinence des travaux accomplis, en en mesurant l'impact sur l'état de nos connaissances ou sur notre vie quotidienne.

3 C'est ce qu'ont fait René Bimbot et ses collaborateurs de toutes disciplines en choisissant parmi l'ensemble des découvertes, celles qui semblaient les plus originales et surtout celles dont l'importance pouvait s'exprimer en conséquences théoriques ou 
pratiques pour les chercheurs (pas nécessairement de la même discipline) ou pour l'homme de la rue.

4 La majorité des découvertes rapportées dans ce livre concernent la physique et plus spécialement la physique nucléaire. D'autres découvertes en biologie, chimie ou en sciences des matériaux sont souvent à la frontière de plusieurs disciplines ou utilisent des concepts d'autres disciplines. Leurs développements ont parfois fécondé d'autres disciplines. Ainsi la sonde ionique " de Castaing » (1962) ou la résonance magnétique nucléaire (RMN, 1978 avec Pierre Grivet) ont trouvé des applications multiples en biologie, en médecine, en métallurgie, en géochimie, etc. Des études sur les propriétés des cristaux liquides, fruit d'une collaboration entre plusieurs équipes ont eu des applications qui font partie de notre paysage quotidien (ex. : l'affichage de l'heure sur nos appareils électroménagers) et ont valu le prix Nobel à Pierre-Gilles de Gennes. Les mathématiques sont évidemment présentes dans ce livre notamment par les travaux de Laurent Lafforgue sur la loi de correspondance de Langlands qui se veut unificatrice de diverses branches des mathématiques (médaille Fields 2002) ou les travaux sur les fractales, qui valurent la médaille Fields en 1989 à Jean-Christophe Yoccoz et tout récemment à Wendelin Werner (2006).

Des travaux originaux, tels ceux de Jean-Louis Marignier sur la reconstitution expérimentale de l'invention initiale de l'héliogravure de Niepce, sont magnifiques par leur apparente gratuité. D'autres travaux (1999), qui analysent les contextes sociaux, économiques, scientifiques et politiques des exhibitions de spécimens humains entre 1877 et 1930 (programme " Zoos humains ») tentent d'expliquer la genèse du racisme ordinaire.

Chaque " découverte » est présentée en une page ou deux, dans une typographie aérée, en un langage qui a cherché à être simple et compréhensible par le plus grand nombre. Des renvois à un glossaire permettent de préciser les concepts. Le résultat est un livre qui aiguise l'envie d'en savoir plus ou d'en comprendre plus.

7 Ce livre, n'est-il pas finalement la défense et illustration du bien-fondé de politiques institutionnelles, associant le CNRS (8\% des personnels du CNRS sont sur ce campus), l'Inserm, l'Inria, l'enseignement supérieur, etc., et des entreprises, qui ont permis au fil du temps le développement de cette énorme concentration de chercheurs travaillant en synergie? Le message que l'on retient est qu'une communauté de scientifiques pluridisciplinaire importante, associée à un lieu de formation universitaire à la recherche, ouverte aux collaborations urbi et orbi, est féconde scientifiquement.

INDEX

Mots-clés : Découvertes, Orsay 
AUTEUR

\section{ISABELLE MARTELLY}

Professeur au Laboratoire de recherche sur la croissance cellulaire, la réparation et la régénération tissulaires (CRRET), Université Paris XII 